$1-2012$

\title{
Wrongful Convictions Do Lower Deterrence
}

Nuno Garoupa

Texas A\&M University School of Law, ngaroup@gmu.edu

Matteo Rizzolli

Follow this and additional works at: https://scholarship.law.tamu.edu/facscholar

Part of the Criminal Law Commons, Law and Society Commons, and the Law Enforcement and Corrections Commons

\section{Recommended Citation}

Nuno Garoupa \& Matteo Rizzolli, Wrongful Convictions Do Lower Deterrence, 168 J. Institutional \& Theoretical Econ. 224 (2012).

Available at: https://scholarship.law.tamu.edu/facscholar/616

This Article is brought to you for free and open access by Texas A\&M Law Scholarship. It has been accepted for inclusion in Faculty Scholarship by an authorized administrator of Texas A\&M Law Scholarship. For more information, please contact aretteen@law.tamu.edu. 


\title{
Wrongful Convictions Do Lower Deterrence
}

\author{
by \\ Nuno Garoupa and Matteo Rizzolli*
}

Received June 8, 2010; in revised form February 6, 2011; accepted April 11, 2011

\begin{abstract}
The conventional result of the theory of the public enforcement of law is that wrongful convictions of innocents are detrimental to deterrence. This proposition has been challenged recently. In some cases, wrongful convictions do not jeopardize deterrence, because they influence equally the innocent and the guilty. Therefore deterrence does not change. We show that, in general, wrongful convictions do lower deterrence. We prove that wrongful convictions do not jeopardize deterrence only in very limited circumstances or under unlikely assumptions. (JEL: K4)
\end{abstract}

\section{Introduction}

In most of the economic literature, judicial errors are usually understood as wrongful convictions of actually innocent defendants and wrongful acquittals of actually guilty defendants. ${ }^{1}$ In the literature on optimal deterrence that followed the seminal work by Becker (1968), wrongful convictions came first into focus with the work of Harris (1970), who extended the model to include the social costs of wrongful convictions. Recent surveys of the standard theory of optimal deterrence show how wrongful convictions are as detrimental to deterrence as wrongful acquittals (for example, Polinsky and Shavell, 2007).

The conventional result that wrongful convictions hurt deterrence is based upon the work of Png (1986). On one hand, wrongful acquittals improve the expected payoffs of committing crime, but, on the other hand, wrongful convictions decrease the

${ }^{*}$ University of Illinois College of Law (corresponding author) and Free University of Bozen-Bolzano, School of Economics and Management. We thank Henrik Lando for the stimulating discussion even if we only agree to disagree. We also thank one anonymous referee, Tom Miceli, and Mitch Polinsky for important comments. We are grateful to Roya H. Samarghandi for editorial assistance. The usual disclaimers apply.

1 These are the so-called outcome errors. Legal scholars also distinguish factual errors, for which the relevant facts are erroneously identified, and legal errors, for which the proper legal standard is mistakenly assessed; see Khanna (2002). We refer only to the first type of errors. 
expected payoffs of staying honest. On balance, an increment in either probability decreases deterrence. Therefore, Png makes two relevant points: (i) wrongful convictions (and not only wrongful acquittals) diminish deterrence; and (ii) wrongful convictions and wrongful acquittals are equally bad in their effect on deterrence. At the margin, one further wrongful conviction induces as many individuals to switch behavior from compliance to noncompliance as one further wrongful acquittal. ${ }^{2}$

In a provocative paper, Lando (2006) questions the conventional result of the theory of the public enforcement of law that wrongful convictions of innocents are detrimental to deterrence. He distinguishes between mistakes of act and mistakes of identity, and claims that, for the latter, wrongful convictions do not jeopardize deterrence. Mistakes of act happen when somebody is convicted for a crime that did not actually happen. As an example, Lando points to the case of speeding tickets, where the police fail to report the actual speed correctly because of measurement errors. But it could be also the case for insider trading in corporate criminal law, or tacit collusion in antitrust law. ${ }^{3}$ These are typically cases for which the principal question faced by the court is whether or not there was any actual crime. These potential crimes are difficult to prove because there is no evident "smoking gun." Mistakes of identity happen when one individual is punished for a crime committed by somebody else. In the context of evident crimes, such as murders and robberies, the wrong person can be incriminated for an act that actually did happen.

The novel argument proposed by Lando is the following. When mistakes of identity happen, and also when criminals can be punished for the crimes of others, then the expected returns to not committing the crime decrease equally for the honest and for the criminal. Thus, individuals do not switch behavior; in other words, deterrence is not jeopardized. In the present paper, we show that Lando's claim can only be true in very limited circumstances or under unlikely assumptions. More generally, it is realistic to suppose that wrongful convictions do lower deterrence as suggested by the conventional literature.

A numerical example is illustrative. Suppose the probability of conviction of a criminal is 0.5 and the fine is fifty dollars. The expected fine is twenty-five dollars. Everyone who derives a benefit higher than twenty-five dollars from committing a crime is not deterred.

The idea developed by Png is the following. Suppose the probability of conviction of an innocent is 0.1. The expected fine paid by an innocent is five dollars. As a consequence, anyone who derives a benefit higher than twenty dollars (twentyfive dollars minus five dollars) from committing a crime is not deterred. Deterrence has been diminished as a consequence of wrongful convictions.

2 In this stream of literature one should also mention the work of Ehrlich (1982), who suggested the hypothesis that the conviction of the innocent may increase (instead of decrease) deterrence if such conviction is perceived by other imperfectly informed would-be offenders in society as a correct conviction of a guilty individual.

3 A wise stock investment may be misread as insider trading, a certain competitivemarket equilibrium may be misunderstood as tacit collusion, and a suicide may be mistaken for a homicide. 
The point raised by Lando is that the example we have developed so far applies only to mistakes of act. When we consider mistakes of identity, a criminal can also be wrongfully convicted. The expected fine of five dollars is borne by both innocents and guilty equally. As a consequence, the threshold is still twenty-five dollars, and deterrence has not been jeopardized. His conclusion is driven by the assumption that the probability of a mistake of identity spreads thin over the entire population of both innocent and guilty individuals (whereas mistakes of act only concern innocents).

However, an important implication of the existence of mistakes of identity has been overlooked. For every wrongful conviction (of either an innocent or a guilty individual) there must be a wrongful acquittal of a factually guilty individual. In other words, for mistakes of identity, one must equalize the number of mistakes with the number of crimes committed in order to balance the demand and the supply for mistakes. We show that, in general, wrongful convictions do lower deterrence. Even if the probabilities of mistakes influence innocents and guilty equally, deterrence goes up because these probabilities of mistake of identity also affect wrongful acquittals. Looking at our numerical example, we propose that if the probability of conviction by mistakes of identity is 0.1 for both guilty and innocent, then the probability of a wrongful acquittal has to go up, for example, to 0.6 in order to have a balance between mistakes of identity and crimes committed. As a consequence the probability of rightful conviction is now 0.4 , and not 0.5 . The critical threshold is again twenty dollars. Deterrence has been jeopardized as a consequence of mistakes of identity.

In this paper we contest the idea that wrongful convictions do not dilute deterrence when we consider mistakes of identity. Notwithstanding, more generally, Lando acknowledges that wrongful convictions may still diminish deterrence for other reasons: (i) given the existence of a criminal opportunity, the relative payoff of staying honest is reduced if others commit a crime and therefore increase the risk of a wrongful conviction; (ii) the conviction of an innocent often implies that the real wrongdoer is free, and this could further dilute deterrence; (iii) the risk of being mistakenly punished for a higher-order crime induces the criminal to commit another, lower-order crime (a standard marginal-deterrence argument). ${ }^{4}$

The paper goes as follows. Section 2 develops a formal model. Final remarks are addressed in section 3 .

\section{The Model}

In this model, there is only one type of crime. ${ }^{5}$ Individuals have to decide whether or not to commit this crime, and each individual can commit the crime only once.

\footnotetext{
${ }^{4}$ As to (iii), the result can be reversed if (as Lando argues) the choice is continuous and not discrete (the wrongdoer can tune the degree of care). Furthermore, wrongful convictions might increase deterrence if correct sentencing for a given crime increases the likelihood of a wrongful conviction in the future.

5 There are different possible interpretations. There are crimes for which both types of errors can happen (such as the speeding example). Alternatively, consider two dif-
} 


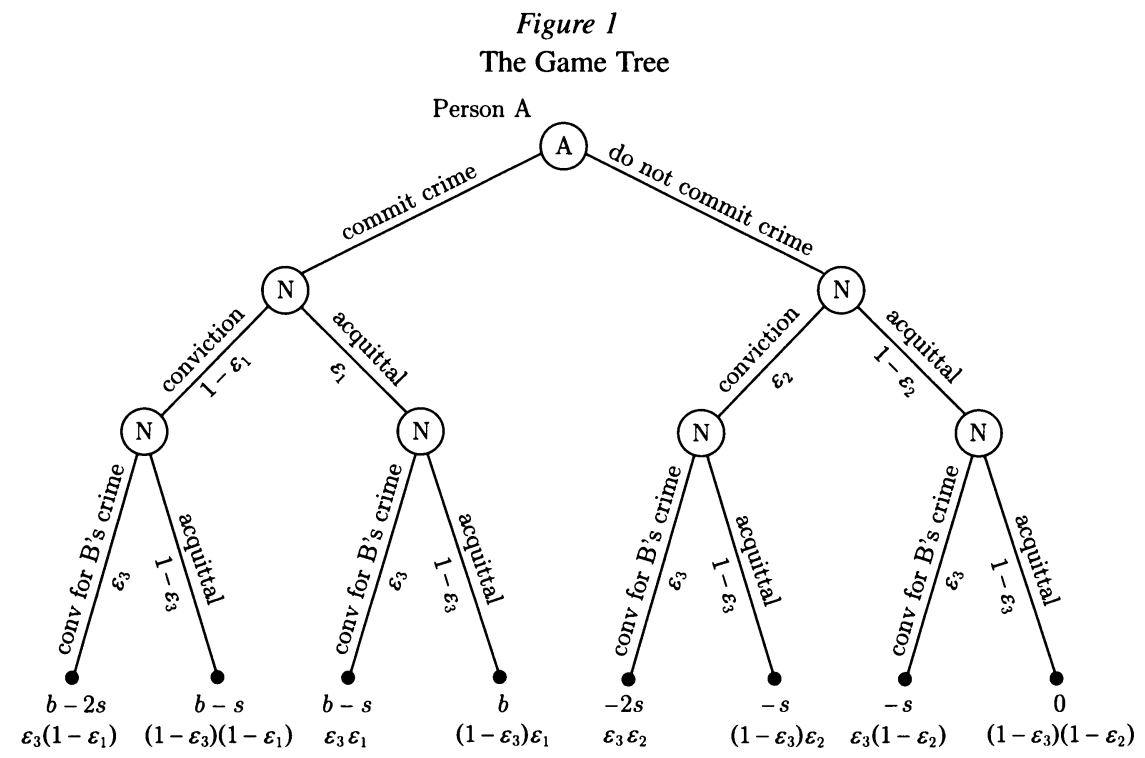

Individuals are then tried in court and sanctioned subject to the two types of errors: wrongful convictions and wrongful acquittals. Let $b$ be the gains to the individual from committing the crime, and $s$ the sanction imposed by the court.

Let us define $\varepsilon_{1}$ as the probability of wrongful acquittal for a crime one has committed (hence a conditional probability given guilt); $\varepsilon_{2}$ as that of wrongful conviction for a crime that has not been committed (a conditional probability given innocence); and $\varepsilon_{3}$ as that of wrongful conviction for someone else's crime. This last probability applies to innocents and guilty alike (hence $\varepsilon_{3}$ is an unconditional probability). Figure 1 summarizes the different possibilities from the viewpoint of person $\mathrm{A}$ when there is another crime committed by person $\mathrm{B}^{6}$

Notice that the game tree describes the most generic game and in principle concerns both mistakes of act and mistakes of identity. We confront here two models, one where there are mistakes of act and the other where there are mistakes of identity. Mistakes of act are convictions for crimes that never happened and thus for which there are no corresponding criminals acquitted. In this case the probabilities of wrongful convictions and wrongful acquittals are independent, and thus an increase in wrongful convictions does not imply any change in the proportion of wrongful acquittals. Mistakes of identity, instead, are crimes for which the wrong

ferent crimes (one to fit mistakes of act and one to fit mistakes of identity) subject to the same social cost and the same probability of being detected.

${ }^{6}$ If $\varepsilon_{3}$ only applies when person $\mathrm{A}$ has not been convicted of crime $\mathrm{A}$, in the context of Figure 1, then Lando's result never holds, because all three errors reduce deterrence. 
person is convicted for a given crime, and for the same crime, a guilty individual is wrongfully acquitted. ${ }^{7}$ In this case, wrongful convictions and wrongful acquittals for a given crime are linked, as the conviction of an innocent person implies the acquittal of the person actually responsible for it.

The expected sanction borne by a criminal is $\left(1-\varepsilon_{1}+\varepsilon_{3}\right) s$, and the expected sanction borne by an innocent is $\left(\varepsilon_{2}+\varepsilon_{3}\right) s$. An individual commits the crime as long as $b \geq b^{*}$, where

$$
b^{*}=\left(1-\varepsilon_{1}-\varepsilon_{2}\right) s .
$$

Let us normalize the population to one and denote by $G(b)$ the cumulative distribution of $b$. Then, $G\left(b^{*}\right)$ is the population of innocents, and $1-G\left(b^{*}\right)$ is the population of criminals. For convenience, define $n=1-G\left(b^{*}\right)$ and therefore $G\left(b^{*}\right)=1-n$, where $n$ is the crime rate.

Under the model developed by Png (1986), there are only mistakes of act, and they affect only innocents:

PNG'S SYMmetric ReSUlt Assume $\varepsilon_{2}>0$ and $\varepsilon_{3}=0$. Wrongful convictions jeopardize deterrence.

The result is immediate from (1). The relationship between $n$ and $\varepsilon_{2}$ is positive, showing that the crime rate goes up with the probability of wrongful convictions.

Let us now assume, as in Lando (2006), that there are only mistakes of identity. The following proposition holds:

\section{LANDO's RESULT Assume $\varepsilon_{2}=0$ and $\varepsilon_{3}>0$. Wrongful convictions do not jeop- ardize deterrence.}

The result is again immediate from (1). Once the probabilities of wrongful convictions of guilty and innocent cancel out, the crime rate is not affected by wrongful convictions. Lando's intuition is that the possibility of occurrence of wrongful convictions also for other criminals undermines the conventional wisdom. If Lando's assumption is correct, then wrongful convictions have no effect on deterrence, while wrongful acquittals diminish deterrence. However, his insight neglects an important balance between mistakes of identity and actual crimes.

In fact, notice that while mistakes of act are convictions for crimes that never happened and thus for which there are no corresponding criminals acquitted, mistakes of identity, instead, are crimes for which the wrong person is convicted for a given crime, and for the same crime, a guilty person is wrongfully acquitted. ${ }^{8}$

${ }^{7}$ Lando argues that these are the cases where the occurrence of a crime is incontrovertible; only the identity of the criminal is questionable. There are of course crimes that are borderline; think for instance of cases of looks-like homicides that in fact are suicides, or of unintentional losses that are taken as thefts (for which thus a mistake of act becomes a mistake of identity).

${ }^{8}$ In the case of mistakes of act, the crime rate is overestimated, as there are more crimes than actual criminals. This should not be a problem as long as the population is sufficiently large. 
Figure 2

The Game Tree under Png's and Lando's Restrictive Assumptions Respectively

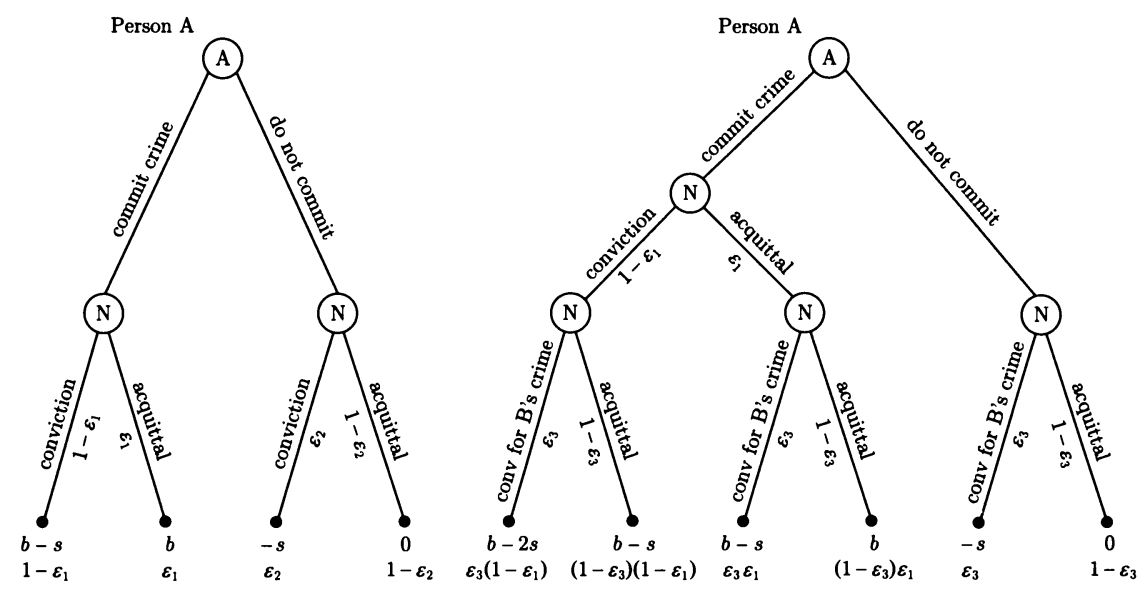

Therefore, if there is a mistake of identity, then there is only one wrongful conviction (either of an innocent or of a guilty person) for every wrongful acquittal. ${ }^{9}$ Given this equality, we can equate the following:

$$
\underbrace{\varepsilon_{1} n}_{\text {supply of errors }}=\underbrace{\varepsilon_{3} n+\varepsilon_{3}(1-n)}_{\text {demand for errors }} .
$$

The expression (2) describes the supply-demand equilibrium in the market for errors when mistakes of identity occur. Applying our notation, we also have that

$$
1-n=G\left[\left(1-\varepsilon_{1}-\varepsilon_{2}\right) s\right] .
$$

Together, (2) and (3) determine $\hat{n}\left(\varepsilon_{2}, \varepsilon_{3}, s\right)$ and $\hat{\varepsilon}_{1}\left(\varepsilon_{2}, \varepsilon_{3}, s\right)$ in equilibrium. Let us now analyze how the equilibrium is perturbed when there is a marginal variation of $\varepsilon_{3}$. We differentiate both equations (2) and (3):

$$
\begin{gathered}
\varepsilon_{1} d n+n d \varepsilon_{1}=d \varepsilon_{3}, \\
d n=g(\cdot) s d \varepsilon_{1} .
\end{gathered}
$$

By substitution, we get

$$
\frac{d n}{d \varepsilon_{3}}=\frac{g(\cdot) s}{n+g(\cdot) s \varepsilon_{1}}
$$

Clearly, from (4), $d n / d \varepsilon_{3}>0$ for all $\varepsilon_{2}$ and $\varepsilon_{3}$. The number of criminals increases with the probability of mistakes of identity. The reasoning is the following: Higher likelihood of wrongful convictions increases the demand for errors. As a consequence, the supply of errors has to increase for the sake of equilibrium. Therefore, necessarily the number of criminals has to increase.

\footnotetext{
9 We can easily generalize the model for the possibility that there is a wrongful conviction for $x$ wrongful acquittals.
} 
From (2) and (3), we can also see that the result obtained by Lando only holds under a specific assumption. By applying total differentiation to (2) and (3), we obtain

$$
d n=\frac{g(\cdot) s d \varepsilon_{3}+n g(\cdot) s d \varepsilon_{2}}{n+g(\cdot) s \varepsilon_{1}} .
$$

Therefore, in order to conclude that $d n=0$ as Lando did, we would need to have $d \varepsilon_{2} / d \varepsilon_{3}=-1 / n$. When the likelihood of mistakes of identity increases, the likelihood of mistakes of act must decrease in a particular way (namely, at rate $-1 / n)$. There is no reason to think that such assumption is satisfied in general, and particularly in the examples offered by Lando.

\section{Final Remarks}

Generally speaking, wrongful convictions do lower deterrence unless some specific relationship exists between mistakes of identity and mistakes of act. The conventional result of the theory of public law enforcement seems to be robust to the possibility that wrongful convictions also affect criminals.

Refuting the generality of Lando's argument has important theoretical and policy implications. Rules of evidence, as well as other characteristics of criminal procedure, all seek to produce as few wrongful convictions as possible even at the cost of allowing many wrongful acquittals. If Lando's insight were of general application, deterrence-based explanations would be flawed, since wrongful convictions should be simply irrelevant. The pro-defendant bias of criminal procedure would have to be explained in other terms. Our model points out that Lando's insight is of little practical applicability. Therefore, our model supports the basic theoretical framework and supports the significant relevance of a growing body of work explaining why wrongful convictions are more socially costly than wrongful acquittals. $^{10}$

\section{References}

Bar-Gill, O. (2004), “The Efficiency of Protecting the Innocent,” Mimeo, New York University.

Becker, G. (1968), "Crime and Punishment: An Economic Approach," Journal of Political Economy, 76, 169-217.

10 Wrongful convictions have a larger effect on deterrence because of activity levels (Kaplow and Shavell, 1994); stigma (Galbiati and Garoupa, 2007); costly investments in precautionary activities (Mungan, 2011); risk and loss aversion (Rizzolli and Stanca, 2012); and costly sanctions (Rizzolli and Saraceno, 2012). Bar-Gill (2004) also collects some of the previous arguments to support the case for a deterrencebased rationale against type-I errors. Departing from the standard setup, Hylton and Khanna (2007) explain the pro-defendant nature of criminal procedure in terms of public-choice mechanisms against prosecutorial misconduct. Mostly along the same lines is the paper by Pyne (2004). 
Ehrlich, I. (1982), "The Optimum Enforcement of Laws and the Concept of Justice: A Positive Analysis," International Review of Law and Economics, 2, 3-27.

Galbiati, R., and N. Garoupa (2007), "Keeping Stigma out of Administrative Law: An Explanation of Consistent Beliefs," Supreme Court Economic Review, 15, 273-284.

Harris, J. R. (1970), "On the Economics of Law and Order," Journal of Political Economy, $78,165-174$.

Hylton, K. N., and V. S. Khanna (2007), "A Public Choice Theory of Criminal Procedure," Supreme Court Economic Review, 15, 61-118.

Kaplow, L., and S. Shavell (1994), "Accuracy in the Determination of Liability," The Journal of Law \& Economics, 37, 1-15.

Khanna, V. S. (2002), "Double Jeopardy as Asymmetric Appeal Rights: What Purpose do they Serve?" Boston University Law Review, 82, 341-403.

Lando, H. (2006), "Does Wrongful Conviction Lower Deterrence?" The Journal of Legal Studies, 35, 327-338.

Mungan, M. C. (2011), "A Utilitarian Justification for Heightened Standards of Proof in Criminal Trials," Journal of Institutional and Theoretical Economics (JITE), 167, 352370.

Png, I. P. L. (1986), "Optimal Subsidies and Damages in the Presence of Judicial Error," International Review of Law and Economics, 6, 101-105.

Polinsky, A. M., and S. Shavell (2007), "The Theory of Public Enforcement of Law," in: A. M. Polinsky and S. Shavell (eds.), Handbook of Law and Economics, Vol. 1, NorthHolland, Amsterdam, Ch. 6.

Pyne, D. (2004), "Can Making it Harder to Convict Criminals Ever Reduce Crime?" European Journal of Law and Economics, 18, 191-201.

Rizzolli, M., and M. Saraceno (2012), "Better that Ten Guilty Persons Escape: Punishment Costs Explain the Standard of Evidence," Public Choice, forthcoming.

- and L. Stanca (2012), "Judicial Errors and Deterrence: Theory and Experimental Evidence," The Journal of Law \& Economics, forthcoming.

Nuno Garoupa

College of Law

University of Illinois

504 E. Pennsylvania Avenue

Champaign, IL 61820

U.S.A.

E-mail:

ngaroupa@illinois.edu
Matteo Rizzolli

School of Economics and Management

Free University of Bozen-Bolzano

Universitätsplatz 1

139100 Bozen-Bolzano

Italy

E-mail:

matteo.rizzolli@unibz.it 